Paper

\title{
Practical Application of Drilling of Compacts
}

\author{
Takahiro Inoue, Isao Shimazoe and Izumi Sato \\ Finesinter Co., Ltd., 438, Daisenji-cho, Kasugai, 486-0812 Aichi, Japan.
}

Received August 1, 2003

\begin{abstract}
SYNOPSIS
The machining of green compacts can lead to manufacturing cost reductions through longer tool life, equipment downsizing, decreased processing times etc. Cost benefits can be gained in particular with materials that are hard to cut, such as sinter hardening materials. We have succeeded in changing product processes for sintered parts with drilled holes, by optimizing processing conditions and tools for improvements in cut surface finish and dimensional accuracy.
\end{abstract}

KEY WORDS

Green machining, Sinter-hardening

\section{Introduction}

Because of its difficulty, a compact with lateral holes are, in general, not produced by die compaction, thus processing cost account for a high manufacturing cost. A particularly major issue is to improve the processing methods for materials, which are hard to cut, such as sinter hardening materials; the hardness after sintering exceeds 50 HRA. As cutting resistance in green machining (application of machining green compacts) is low, it can bring cost reduction benefits in terms of longer tool life, downsized equipment, reduced processing times etc. At the same time, environmental benefits are also to be achieved, through the re-use of metal shavings and the elimination of lubricants.

However, in the processing of brittle green compacts with low strength, there are problems such as chipping of peripheral edges of the machined area, roughness of the cut surface, inadequate dimensional accuracy etc. In recent years, published research has tended to concentrate on improving the strength of compacts as a method to solve these problems (improved strength through warm compaction $^{1)}$ and resin addition ${ }^{2)}$ ). These methods incur increases in raw material costs and require changes in equipment such as dies and presses.

We, therefore, aimed to realize a practical application of green machining to products by improving processing methods for normal compacts $\left(6.8-7.2 \mathrm{Mg} / \mathrm{m}^{3}\right)$. As the development procedure, we first used test pieces to evaluate suitable processing conditions to ensure certain properties, such as a reduction in chipping and an improved cut surface finish. Then, based on those results, we carried out processing on actual parts, and realized mass production capability. The part selected (shown in Fig. 1) was an engine part made of a sinter hardening material (HOEGANAES HP-1) with a $\phi 20$ hole drilled through it.

\section{Experiment}

\subsection{Evaluation of test pieces}

First, test pieces were used for an evaluation of the properties to obtain the processing conditions. $10 \mathrm{~mm}$ thick plates were used as test pieces. The material used was HOEGANAES HP $-1+0.5 \%$ Gra $+0.8 \%$ lub, with a mold density of $6.9-7.0 \mathrm{Mg} / \mathrm{m}^{3}$. The equipment used was

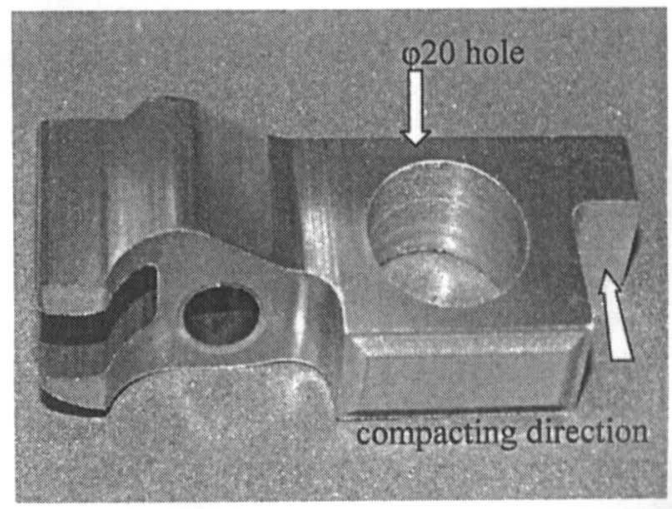

Fig.1 Shape of parts. 
Varimec SSP3-4100B drilling unit (with X-Y slide unit) manufactured by SUGINO MACHINE LTD., and the tools used were a drill (KOBELCO TOOL Co. SD) and endmill (KOBELCO TOOL Co. 2MS).

The following properties were evaluated:

Chipping of peripheral edges of the processed area (measured by tool maker's microscope)

Roughness of cut surface $(\lambda c=0.8 \mathrm{~mm}, \mathrm{~L}=8 \mathrm{~mm})$

Dimensional accuracy (bore checker, or roundness measuring instrument)

\subsection{Evaluation of actual products}

Based on test results obtained by the test pieces, evaluation was carried out on actual parts. In view of mass production capability, processing tests were carried out to identify the problems, and further to analyze the factors involved therein. Finally, these results were used as the basis for mass production processes.

\section{Results and Discussion}

\subsection{Evaluation of test pieces}

\subsubsection{Chipping of outlet edge}

When a hole was drilled in the compact, significant chipping occurred around the hole edge at the outlet side, as shown in Fig. 2-a. In particular, the greater the cutting feed, the greater the extent of the chipping, with nicks reaching sizes up to $3 \mathrm{~mm}$. In order to prevent such chipping, a backup jig was fixed to the edge of the test piece at a

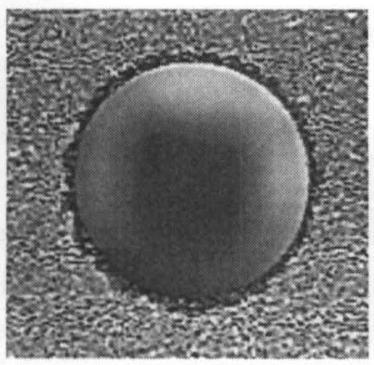

2-a.Without backup jig

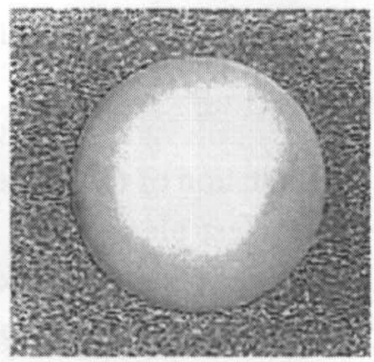

2-b.With backup jig (clearance $0.03 \mathrm{~mm}$ )
Fig.2 Chipping of outlet edge of hole (tool: $\varphi 5$ drill, cutting speed: $1000 \mathrm{~min}^{-1}$, feed speed: $36 \mathrm{~mm} \cdot \mathrm{min}^{-1}$ ).

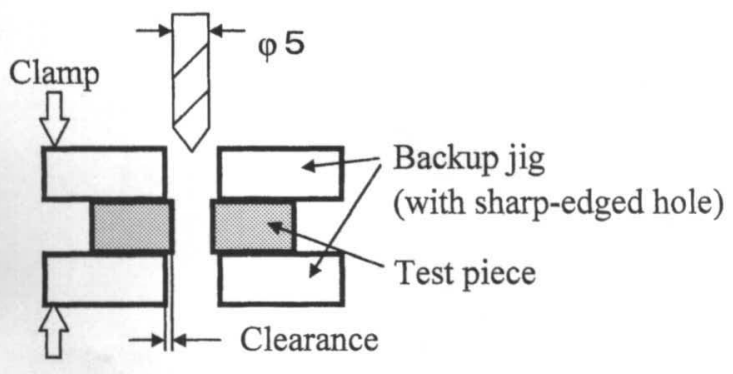

Fig.3 Backup jig for drilling test. constant pressure. As a result, it was possible to greatly reduce the extent of chipping, as shown in Fig. 2-b. Another benefit of the backup jig was that there were no large fluctuations, even with a change in feed speed (Fig. 4), and it is therefore possible to reduce the size of the chipping by reducing clearance of backup jig (Fig. 5).

\subsubsection{Roughness of cut surface}

The appearance of the cut surface is shown in Fig. 6. Holes exist within the smooth cut surface, caused by falling powder. Due to these holes, the cut surface was rougher when compared to drilling after sintering. As shown in Fig. 7, the greater the feed speed, the greater the amount of

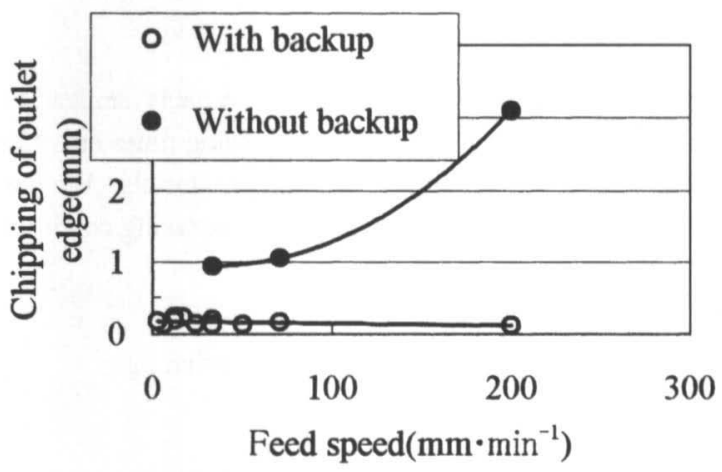

Fig.4 Relationship between chipping of outlet edge and feed speen (tool: $\varphi 5$ drill, cutting speed: $1000 \mathrm{~min}^{-1}$, clearance: $0.03 \mathrm{~mm}$ ).

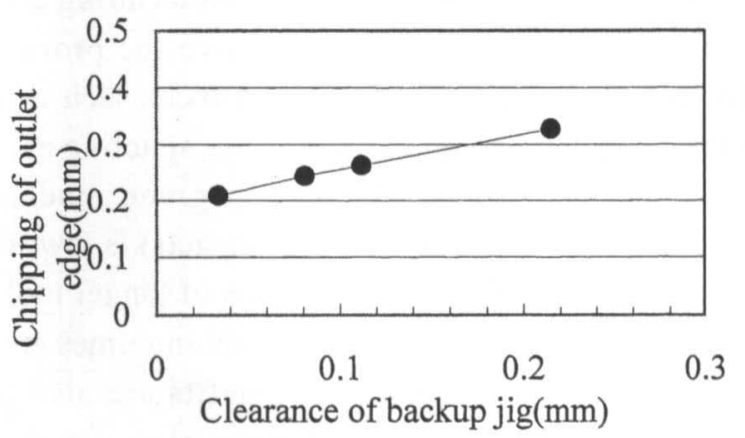

Fig.5 Relationship between chipping of outlet edge and clearance of backup jig (tool: $\varphi 5$ drill, cutting speed: $5000 \mathrm{~min}^{-1}$, feed speed: $\left.180 \mathrm{~mm} \cdot \mathrm{min}^{-1}\right)$.

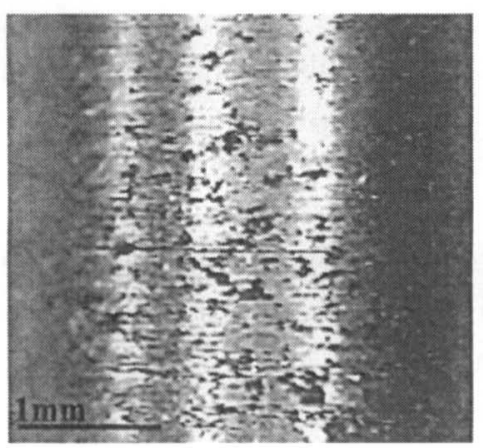

Fig.6 Cut surface after drilling (tool: $\varphi 5$ drill, cutting speed: 5000 $\mathrm{min}^{-1}$, feed speed: $180 \mathrm{~mm} \cdot \mathrm{min}^{-1}$ ). 
material falling from the surface, and the worse the cut surface finish. Therefore, the cut surface could be improved by reducing the feed speed, but radical reduction of the feed speed leads to shake caused by the cutter sliding on the surface, and also to the deterioration in tool life.

\subsubsection{Dimensional accuracy}

Fig. 8 shows the dimensional accuracy for the diameter of a hole cut by green machining. Drilling was carried out after verifying the optimal processing conditions to obtain the best dimensional accuracy. Dimensional accuracy includes positioning accuracy, cylindricity and variations. However, dimensional accuracy after sintering varies depending on sintering conditions etc.

3.2 Evaluation of actual products

Cracks occurred when a $\phi 20$ hole was drilled in the product based on the results of the basic evaluation. The cracks started at a point $2 \mathrm{~mm}$ before the drill penetrated through to the other side. The cracks occurred at points $A$, $\boldsymbol{B}$ and $\boldsymbol{D}$ in Fig. 9, starting from the lower outer edge. We analyzed the factors causing these cracks.

First, FEM analysis was conducted to calculate the stresses that existed in the product (Fig. 10). Analysis conditions were set up such that the thrust load was $498 \mathrm{~N}$ at $2 \mathrm{~mm}$ before the drill penetrated to the other side. Under

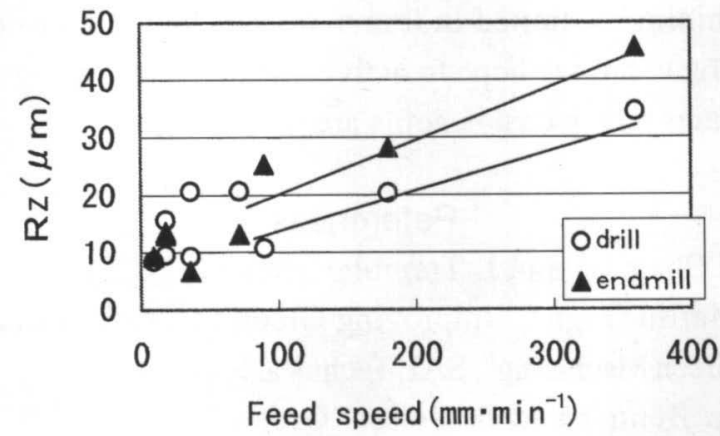

Fig.7 Relationship between roughness of cut surface and feed speed (tool: $\varphi 5$ drill, cutting speed: $1000 \mathrm{~min}^{-1}$ ).

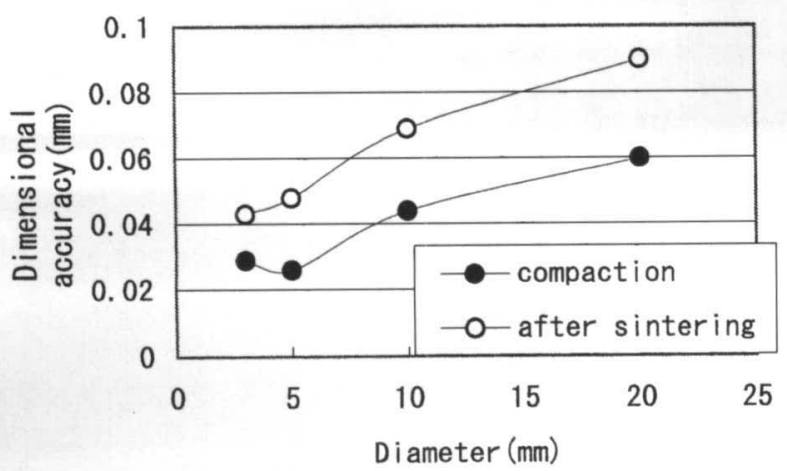

Fig.8 Dimensional accuracy of green machining with appropriate tools and processing conditions. these conditions, FEM analysis showed that the point at which the stress becomes its maximum was $\boldsymbol{A}$, but in the actual drilling process, point $\boldsymbol{B}$ cracked first. In order to clarify the reasons for this difference, analysis was made of other factors. No correlation was observed between the cracks and residual stress and mold density distribution at the time of molding.

Here, the actual distortion to the product was measured by strain gauges (Fig. 11). The load corresponds to vertical force of cutting. In this case, the results of point $A$ is the

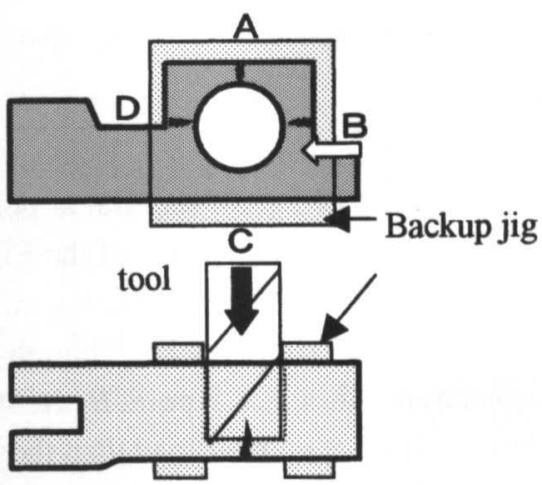

Fig.9 Starting point of crack.

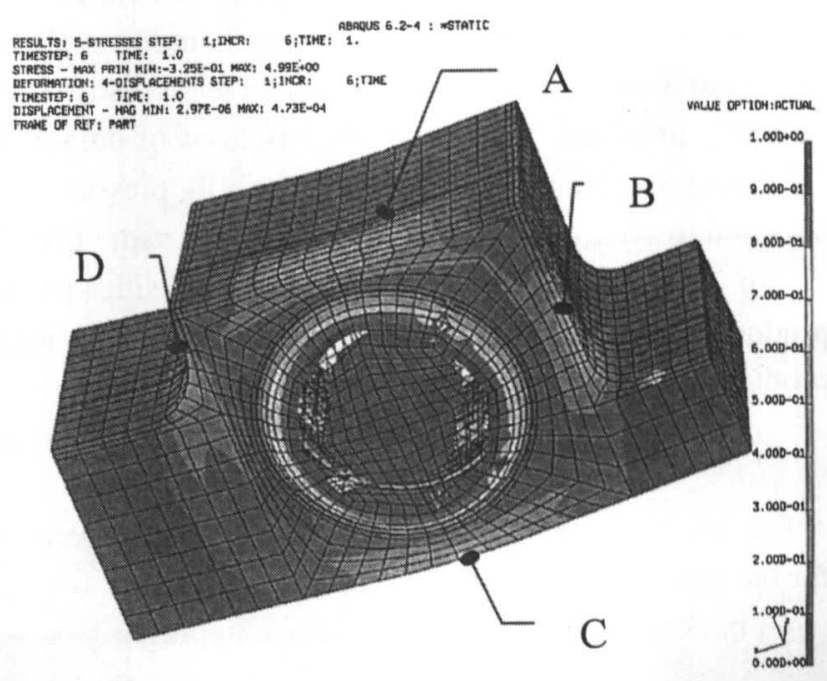

Fig.10 Result of FEM analysis.

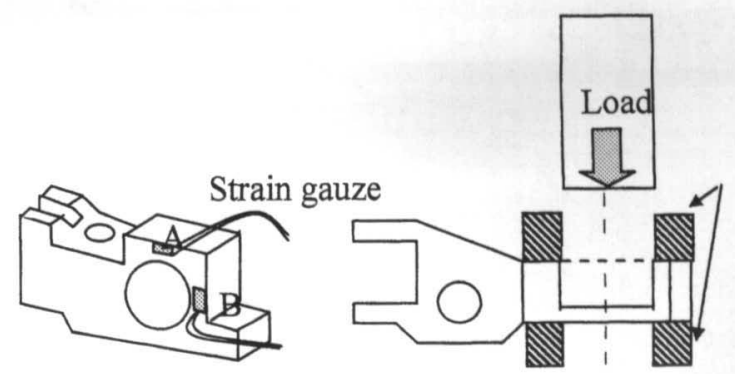

Fig.11 Measurement of distortion in product while cutting. 


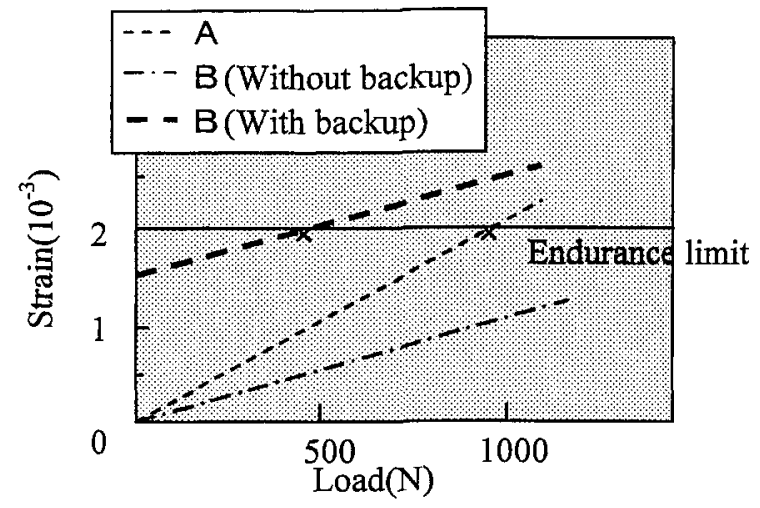

Fig.12 Strain in the product from cutting and backuo stress.

same as those of the FEM analysis. But at point $B$, cracks apper under a lower load than those of the FEM analysis. Fig. 12 shows the relationship between strain at point $A$ and $B$ and vertical load (in Fig. 11). Though the pressure of backup creates tensile stress at point $B$, the strain reached to the endurance limit at a lower load than those without it. The reason for the tensile stress at point $B$ was that the product was not in a completely parallel position, and the clamp pressure was therefore unevenly distributed, causing localized tensile stress. We verified that clamping at plastic or a similar material would establish an even distribution of clamp pressure, but there were problems of durability for mass production. Finally, the backup jig pressure was adjusted to control the tensile stress. At the same time, a clamp to prevent cracks was applied to the sides of the product, thus enabling quality to be maintained under mass production conditions (Fig. 13).

\section{Conclusion}

The following three points must be taken into consideration for the machining of a normal compact.

(1) A backup jig is essential to reduce chipping.

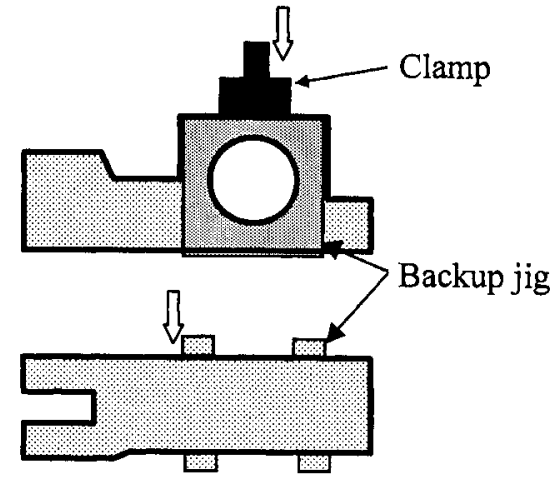

Fig.13 Method of backup and crack prevention in mass priduction.

(2) It is necessary to establish suitable processing conditions and use tools that suited to the shape and properties of the material being processed.

(3) It is necessary to consider clamping methods according to the shape of the product.

When evaluating process capability under mass production conditions, it is also necessary to take into consideration tool wear, and deformation during sintering.

The product evaluated here is already being massproduced. An evaluation of green machining is also currently being carried out on various other products. Green machining is limited in terms of shape and dimensional accuracy, but we hope to actively use this technology for products where cost benefits are promising.

\section{References}

1) F.Chagnon and L.Tremblay: Sylvain St-Laurent and Martin Gagne, "Improving Green Strength to Enable Green Machining", SAE Technical Papers 1999-01-0337.

2) A. Benner and P. Beiss: "Green Turning of Warm Compacted PM steels", Powder Metallurgy, 44(4) (2001)299-303. 